\title{
Atividade e Interação na Rede Social Educacional Redu
}

\author{
Marina de Lira P. Mota ${ }^{1}$, Silvio R. B. Barreto Campello ${ }^{1}$, Raquel R. S. de Oliveira ${ }^{1}$ \\ ${ }^{1}$ Departamento de Design \\ Universidade Federal de Pernambuco (UFPE) - Recife, PE - Brasil \\ inamota@gmail.com, sbcampello@gmail.com, rrsdeoliveira@gmail.com
}

\begin{abstract}
This paper analyzes the use of the REDU Educational Social Networking in the teaching-learning process, in other words, how the platform resources are used and possible usability problems may hinder this process. Principles of Interaction Design were used to support Activity Theory, which was helpful in all stages of research. The results showed a tension between the goal of the students and the teacher in the activity, who wanted to provide collaborative spaces for teaching and learning.
\end{abstract}

Resumo. Este trabalho analisa o uso da Rede Social Educacional REDU no processo de ensino-aprendizagem, ou seja, de que forma os recursos da plataforma são utilizados e que possíveis problemas de usabilidade podem atrapalhar este processo. Os princípios do Design de Interação foram utilizados à luz da Teoria da Atividade, cuja aplicação apresentou utilidade em todas as fases da pesquisa. Os resultados demonstraram uma tensão entre os objetivos dos alunos e do professor na atividade, que pretendia proporcionar espaços colaborativos de ensino-aprendizagem.

\section{Introdução}

As Tecnologias da Informação e Comunicação (TICs) vêm se mostrando como um dos recursos que podem promover inovação no aprendizado. Neste contexto, encontram-se as redes sociais virtuais, popularizadas com a chegada da Web 2.0, as quais permitem altos níveis de interação e colaboração no compartilhamento do conhecimento.

As comunicações mediadas por computador, segundo Morrison (2013), devem facilitar os processos de comunicação, pensamento crítico e pensamento criativo, a fim de garantir uma boa aprendizagem. O autor ainda defende que não é apenas a ferramenta que faz parte desse processo, é o conjunto completo: o design da ferramenta, o uso inteligente dos recursos dessa ferramenta e as tarefas de aprendizagem propostas.

Sendo assim, os modelos teóricos que proporcionem a ampliação do contexto de uso podem auxiliar na análise e avaliação dessas ferramentas mediadoras da aprendizagem. Um desses modelos teóricos é Teoria da Atividade (TA), originada na Psicologia Cognitiva soviética e que foi utilizada neste trabalho como apoio aos princípios do Design de Interação.

O objeto de estudo foi a Rede Social Educacional REDU, cuja plataforma apresentou-se inserida em uma atividade educacional com alunos de Ensino Médio de escolas públicas durante o Curso de Iniciação ao Trabalho da Escola Nacional de Seguros (FUNENSEG) em Pernambuco.

O objetivo deste trabalho é identificar quais características da atividade educacional influenciam no uso dessa ferramenta, por exemplo, os objetivos dos 
participantes, seus papéis e as regras estabelecidas. Além disso, analisar os possíveis problemas de usabilidade na plataforma REDU que podem ter influenciado no processo de ensino-aprendizagem.

O artigo está estruturado da seguinte maneira: a seção 2 apresenta os principais conceitos referentes às Redes Sociais Virtuais e à sua aplicação na educação, além de uma breve descrição da plataforma REDU, objeto de estudo deste trabalho. A seção 3 traz conceitos do Design de Interação, além da descrição das categorias de usabilidade utilizadas. A seção 4 apresenta a Teoria da Atividade, seus principais modelos e princípios. A metodologia utilizada está descrita na seção 5 e a seção 6 apresenta a discussão dos resultados deste trabalho.

\section{As Redes Sociais Virtuais (RSV)}

O termo rede (network) adquiriu diversos significados, entre eles: sistema de nodos e elos, uma estrutura sem fronteiras e uma comunidade não geográfica. Nas redes sociais, há uma valorização das relações informais em detrimento das estruturas hierárquicas. Os participantes, autônomos, unem ideias e recursos em torno de valores e interesses compartilhados [Marteleto 2001]. Com a Web 2.0, as redes sociais passaram a existir também virtualmente. Trata-se de serviços baseados na Web que permitem que os indivíduos construam um perfil público ou semi público, articulem conexões com outros usuários e visualizem as conexões feitas por estes outros usuários [Boyd e Ellison 2007].

Tendo em vista a grande variedade de recursos disponíveis, a possibilidade de gerar ambientes colaborativos e o uso constante por grande parte das pessoas, tem crescido o uso das redes sociais virtuais na educação. Patterson e Lockyer (2008), afirmam que vários pesquisadores analisaram as interações que acontecem nas redes e identificaram aspectos interessantes para a educação como a troca de ideias, feedback das atividades dos colegas e engajamento no pensamento crítico.

Como essas interações são feitas de maneira horizontal, os papéis dos professores e alunos podem mudar. Os professores não são mais vistos como os detentores absolutos do conhecimento, mas como agentes mediadores. Segundo Machado e Tijiboy (2005), com tantas possibilidades, o professor pode acabar perdendo o controle do ambiente e os alunos precisam ter bastante autonomia e responsabilidade. Portanto, a utilização das redes sociais virtuais no ensino deve vir acompanhada, além de um mínimo de domínio técnico, de uma visão histórica e social. Os professores podem contribuir para o aprofundamento das temáticas discutidas nesses espaços e orientar as discussões, auxiliando no aprofundamento dos temas, na síntese de ideias, no levantamento de aspectos significativos e na análise crítica dos dados [Machado e Tijiboy 2005].

\subsection{A Plataforma REDU}

O REDU faz parte deste universo das RSV e representa um ambiente de aprendizagem e ensino que foi criado a partir da necessidade de ampliar o meio escolar e proporcionar uma maior interação entre os atores envolvidos. Dessa forma, alunos, professores e instituições têm a possibilidade de tornar a aprendizagem um processo contínuo que vai além dos muros das escolas [Abreu et al., 2011]. 
A plataforma possui uma estrutura onde a instituição de ensino, ou um professor independente, faz o cadastro de um Ambiente de Aprendizagem. Neste ambiente, será inserido os Cursos, depois as Disciplinas e, por último, as Aulas, organizadas através de Módulos. Além disso, é um ambiente de rede social, permitindo níveis de interação mais flexíveis. Logo, alunos e professores podem trocar informações por chat, mural de discussão, mensagens privadas, etc. A tabela 1 apresenta os recursos oferecidos na plataforma REDU.

\section{Tabela 1. Recursos da Plataforma REDU}

\begin{tabular}{|l|l|}
\hline Mural de Discussão & Espaço para compartilhamento de informações e debates. \\
\hline Pedir ajuda & Botão utilizado para sinalizar dúvidas de alunos no mural. \\
\hline Mensagens Privadas & Apenas podem ser enviadas para seus contatos do REDU. \\
\hline Chat & $\begin{array}{l}\text { Os usuários conversam em pares, não é possível conversas } \\
\text { entre grupos maiores. }\end{array}$ \\
\hline Módulos & Espaços onde são organizados os arquivos de aula. \\
\hline Arquivos de Aula & $\begin{array}{l}\text { Conteúdos de aulas, que podem ser vídeos, apresentações em } \\
\text { slides, documentos simples e exercícios (formato de quiz). }\end{array}$ \\
\hline Arquivos de Apoio & Arquivos complementares à aula. \\
\hline Relatórios & $\begin{array}{l}\text { Permite a visualização de informações estatísticas sobre a } \\
\text { participação dos alunos no REDU. }\end{array}$ \\
\hline Aula finalizada & $\begin{array}{l}\text { O usuário marca este ícone sinalizando que finalizou a aula, } \\
\text { permitindo a autorregulação e organização de seus estudos. }\end{array}$ \\
\hline Marcação de estrelas & O aluno avalia a aula do professor (1 a 5 estrelas). \\
\hline Compartilhar & $\begin{array}{l}\text { Compartilhar o conteúdo das aulas em outros lugares da } \\
\text { Internet, como e-mail, Facebook, Twitter, Linkedin, etc. }\end{array}$ \\
\hline Apagar luzes & $\begin{array}{l}\text { Permite que o fundo da tela fique na cor preta, possivelmente } \\
\text { para deixar o ambiente mais agradável para a leitura. }\end{array}$ \\
\hline
\end{tabular}

\section{Design de Interação}

Segundo Preece et al. (2013) o termo Design de Interação pode ser definido como "projetar produtos interativos para apoiar o modo como as pessoas se comunicam e interagem em suas vidas cotidianas, seja em casa ou no trabalho". O objetivo de um projeto interativo vai depender da finalidade de criação daquele artefato. Ele pode ser um artefato estimulador da criatividade, ou que permita comunicações rápidas, ou ainda que seja seguro na sua utilização, para evitar que acidentes aconteçam. Sendo assim, Preece et al. (2013) separam as metas do Design de Interação em "Metas de Usabilidade" e "Metas da Experiência do Usuário". Com objetivo de verificar se as metas de usabilidade foram alcançadas, especialistas criaram as "categorias de usabilidade" - pontos específicos que devem ser considerados, tanto no projeto quanto na avaliação do design -, a fim de garantir um bom uso por parte das pessoas.

Nielsen (1994) apud Nielsen (1995) elaborou um conjunto de heurísticas derivadas da análise de 249 problemas de usabilidade. São chamadas de "As 10 
heurísticas de ouro". Norman (2006) também cita alguns princípios de usabilidade em seu livro "O design do dia-a-dia". Finalmente, Jordan (1998) apresenta 10 princípios de usabilidade chamados de Princípios de Design "Usável".

Algumas dessas categorias são citadas pelos mesmos autores, como por exemplo: (1) feedback, ou seja, informar ao usuário sobre o resultado de suas ações no sitema; (2) affordance, que refere-se ao atributo de um objeto que permite às pessoas saber como utilizá-los, ou seja, "dar uma pista"; (3) priorização da funcionalidade e informação mais importante, ou seja, o sistema deve ser projetado a fim de que as informações mais importantes sejam facilmente acessadas; (4) clareza visual, o sistema deve ser claro e objetivo, para que o usuário leia rapidamente e não entre em confusão; (5) controle do usuário, o sistema deve permitir que o usuário tenha o máximo de controle sobre as ações realizadas.

Já as metas da experiência do usuário são referentes à experiência de uso, do ponto de vista dos próprios usuários [Preece et al. 2013]. Elas tratam das experiências emocionais e sensoriais, ou seja, o que o usuário sente ao usar determinado produto. Para verificar se essas metas estão sendo alcançadas, podem ser realizadas análises qualitativas, quantitativas ou, como costuma acontecer bastante, uma combinação das duas. O uso de frameworks teóricos para estruturar a análise e investigação pode levar a insights adicionais [Preece et al. 2013]. Um desses frameworks que vem sendo bastante utilizado para apoiar o processo do Design de Interação é a Teoria da Atividade, que será discutida a seguir.

\section{A Teoria da Atividade}

A Teoria da Atividade (TA) possui raízes muito antigas, datadas do século XVIII e XIX, porém a versão mais discutida atualmente vem da psicologia histórico-cultural soviética fundada por Vygotsky, acompanhada por seus seguidores Leontiev e Luria [Kuutti, 1996]. Kuutti (1996) afirma que a solução oferecida pela TA é que o mínimo de contexto significativo para ações individuais deve ser incluído na unidade de análise. Esta unidade seria justamente a atividade.

Leontiev (1981) apud Kaptelinin (2013) desenvolveu um modelo de atividade com base nas ideias propostas por Vygotsky. No seu sentido amplo, a atividade é a interação do sujeito com o mundo. O modelo mais primitivo basicamente defende que a interação humana pode ser descrita como o processo que relaciona o sujeito e o objeto, onde o sujeito possui suas próprias necessidades e interage com objetos do mundo a fim de satisfazê-las [Kaptelinin, 2013]. Essa abordagem se concentra em atividades individuais dos seres humanos, mas a noção de "sujeito" não se limita a um único indivíduo. Outros tipos de entidades, como animais, times e organizações também podem ter suas necessidades e, neste caso, podem ser sujeitos de atividades [Kaptelinin e Nardi 2006].

A partir das ideias de Leontiev sobre as atividades individuais dos seres humanos, Kaptelinin e Nardi (2006), baseados em Wertsch (1981), identificaram e relataram os seguintes princípios básicos: (1) orientação à objetos, ou seja o sujeito interage com objetos no mundo, a fim de satisfazer suas necessidades. Este objeto pode ser algo tangível ou não; (2) estrutura hierárquica da atividade, que parte do princípio que a atividade é formada por ações que por sua vez é formada por operações. Atividade está ligada à um motivo, as ações, à obtenção de metas, e operações, à 
processos inconscientes; (3) mediação, ou seja, a interação entre sujeitos e objetos é feita através de artefatos mediadores que podem ser ferramentas materiais (martelos, facas, etc.) ou imateriais (conceitos, ideias, etc.); (4) internalização e externalização, no primeiro processo, os sujeitos absorvem informação e no segundo, liberam informação; (5) desenvolvimento, pois entender como o objeto da atividade tem se transformado no decorrer do tempo contribui para a compreensão de seu estado atual.

Essa relação entre o sujeito e objeto da atividade não é tão simples na prática. Sendo assim, além do sujeito e do objeto, um terceiro componente principal, a comunidade (que compartilha o mesmo objeto), foi adicionado. Então, duas novas relações são formadas: sujeito-comunidade e comunidade-objeto [Kuutti 1996]. Esse mesmo autor explica que este modelo sistemático, que foi baseado na conceituação de Engeström (1987), contém três mútuas relações entre sujeito, objeto e comunidade. Todas elas também são relacionadas, conforme mostra a Figura 1.

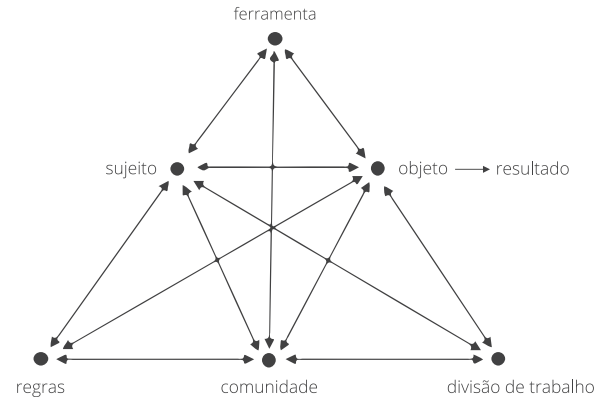

Figura 1. Modelo de um Sistema de Atividades.

A relação entre sujeito e objeto é mediada pela ferramenta, a relação entre sujeito e comunidade é mediada pelas regras e a relação entre objeto e comunidade é mediada pela divisão de trabalho. A ferramenta pode ser qualquer coisa usada na transformação do processo, incluindo ferramentas materiais e imateriais. Já as regras podem ser explícitas ou implícitas e cobrem normas, convenções e relações sociais entre a comunidade. A divisão de trabalho refere-se a implícita ou explícita organização da comunidade no processo de transformação do objeto em resultado [Kuutti 1996].

É importante ressaltar que os elementos da atividade estão em constante transformação e desenvolvimento. Esse desenvolvimento é entendido como um processo conduzido por contradições [Kaptelinin 2013]. Engeström (1987) apud Kaptelinin (2013) identificou quatro tipos de contradições nos sistemas de atividades: (1) contradições primárias, que são contradições internas em cada elemento do sistema de atividades; (2) contradições secundárias, que são contradições entre os elementos do sistema de atividades; (3) contradições terciárias, que são contradições entre as formas existentes e potenciais do sistema de atividades; (4) contradições quartenárias, que se referem a contradições entre diferentes sistemas de atividades.

A lógica tradicional considera contradições como um indicador de problemas que precisam ser resolvidos. Elimina-las permite a criação de um sistema perfeitamente lógico [Kaptelinin 2013]. 


\section{Metodologia}

A pesquisa consistiu na análise de uma atividade educacional usando o REDU como apoio às aulas presenciais do Curso de Iniciação ao Trabalho do Programa Amigo do Seguro, oferecido pela Escola Nacional de Seguros (FUNENSEG), durante os meses de Junho/Julho de 2013, em Recife, PE. A experiência aqui descrita é referente apenas às atividades realizadas na plataforma REDU durante a disciplina de "Conceitos Básicos de Seguros", que teve início no dia 8 de Julho de 2013 finalizando no dia 17 de Julho de 2013. Os alunos são provenientes de escolas públicas estaduais, do $1^{\circ}$ ao $3^{\circ}$ ano do Ensino Médio, possuem de 16 à 20 anos e residem no Estado de Pernambuco. A turma era composta de 43 alunos no total.

\subsection{Coleta de Dados}

A primeira etapa da pesquisa teve como objetivo traçar o perfil dos alunos e suas experiências anteriores em relação ao uso da Internet. A maioria dos alunos responderam possuir internet em casa, passam de $1 \mathrm{~h}$ à $3 \mathrm{~h}$ navegando e as atividades que mais realizam é interagir nas redes sociais (principalmente Facebook) além de fazer pesquisas escolares em sites como Brasil Escola, Info Escola, Wikipédia e Youtube.

A segunda etapa da pesquisa teve como objetivo entender como os alunos utilizaram o REDU para a aprendizagem, se tiveram dificuldades durante esse processo e em que etapas específicas essas dificuldades ocorreram.

A Teoria da Atividade foi utilizada nessa etapa em dois momentos. Primeiro, através do princípio da Estrutura Hierárquica da Atividade (tríade Atividade-AçãoOperação) foi possível identificar todos os níveis da atividade e, assim, poder visualizar as ações e operações utilizadas pelos alunos para concretização de suas metas dentro do sistema. As ações analisadas foram desde o cadastro no REDU até o acesso aos arquivos de aulas. Já as operações foram desde digitar os dados de cadastro até cliques em aulas e botões. Essas ações possíveis no REDU foram identificadas com base nas informações presentes no Guia Básico, localizado na Central de Ajuda do sistema além da observação e participação em outras atividades usando o REDU.

Nessa mesma fase da pesquisa, o Sistema de Atividades foi utilizado para identificar aspectos da atividade que seriam relevantes para a análise. Os elementos foram identificados: (1) observando as ações dos alunos em 2 aulas presenciais; (2) observando as ações dos alunos no REDU; (3) observando as ações dos alunos em um grupo do curso criado por eles mesmos no Facebook.

Com base nas informações da tabela da tríade Atividade-Ação-Operação e nas observações das atividades, foi-se estruturado um questionário, contendo 10 questões fechadas e 3 questões abertas. O questionário foi entregue aos alunos durante o último dia de aula e 38 dos 43 alunos matriculados no curso responderam a essas questões. Também foi realizada uma entrevista não estruturada com o professor, a fim de identificar seus objetivos e práticas na atividade.

\subsection{Análise de Dados}

Os principais focos da análise foram: (1) a identificação de possíveis problemas de usabilidade que possam ter influenciado na realização de tarefas no REDU; (2) as relações entre os elementos do sistema de atividades de Engeström (1987) apud Kaptelinin (2013) e as possíveis contradições entre eles. 
Como foi visto, um Sistema de Atividades está em constante transformação, o que pode gerar contradições entre seus elementos. Nessa pesquisa foi possível identificar algumas dessas contradições, nesse caso secundárias, que são entre os elementos do sistema.

As contradições foram organizadas com base no esquema proposto por Mwanza (2000). Assim como no trabalho dessa autora, as duas principais relações focadas foram entre sujeito-objeto e comunidade-objeto, que foram analisadas em termos de seus mediadores: ferramentas, divisão de trabalho e regras.

Tabela 2. Relações entre os elementos do Sistema de Atividades

\begin{tabular}{|l|l|l|}
\hline Sujeito & Ferramenta & Objeto \\
\hline Sujeito & Regras & Objeto \\
\hline Sujeito & Divisão do Trabalho & Objeto \\
\hline Comunidade & Ferramenta & Objeto \\
\hline Comunidade & Regras & Objeto \\
\hline Comunidade & Divisão do Trabalho & Objeto \\
\hline
\end{tabular}

Os possíveis problemas de usabilidade que podem ter influenciado na realização de tarefas no REDU foram analisados, especificamente, observando a relação do sujeito com a ferramenta e da comunidade com a ferramenta.

\section{Discussão dos Resultados}

A Figura 2 exibe os aspectos mais importantes da atividade, representados pelo modelo do Sistema de Atividades de Engeström (1987) apud Kaptelinin (2013).

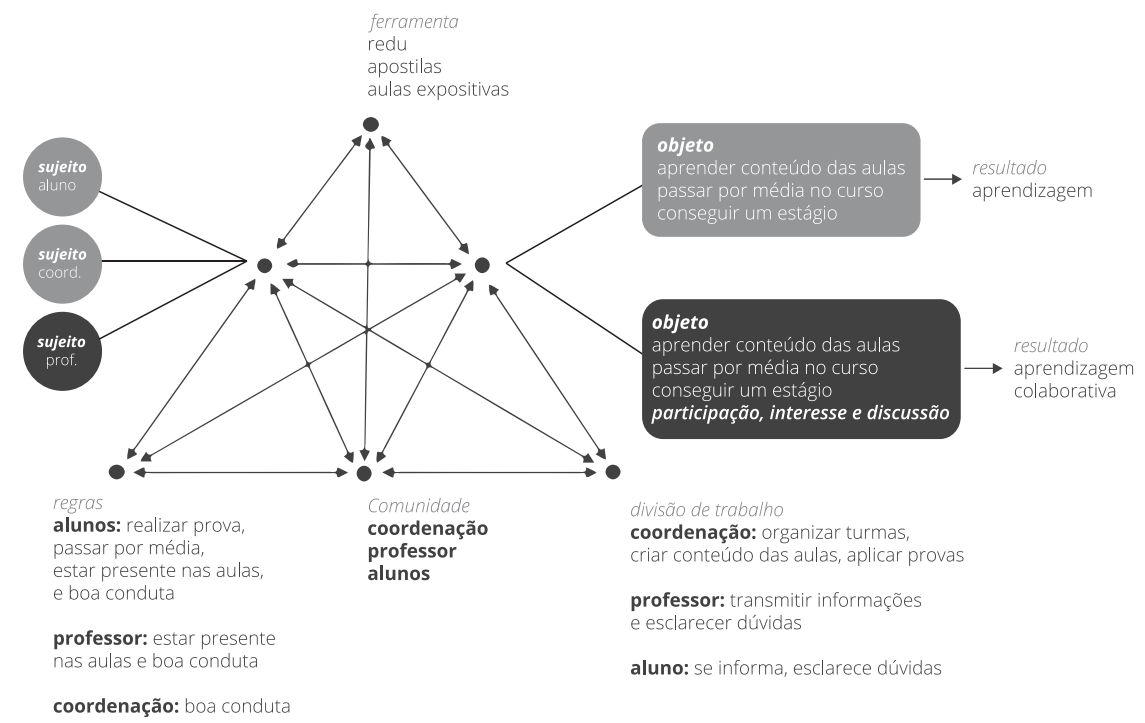

Figura 2. Atividade Educacional representada pelo Sistema de Atividades.

A principal contradição identificada foi que a comunidade não compartilhava do mesmo objeto. O professor tentava propor métodos mais colaborativos e participativos, demonstrando que utilizava o REDU com o objetivo de fazer com que os alunos se engajassem nas aulas, se interessando e debatendo não só sobre o conteúdo padrão mas 
também pelo material extra disponibilizado. Já o principal objetivo dos alunos naquela atividade era passar por média no curso e conseguir um estágio no mercado de trabalho, informações recolhidas com base na observação de relatos de alunos em um grupo que eles mesmos criaram no Facebook.

Foi identificado que a própria coordenação do curso mantém uma metodologia de ensino tradicional, baseada apenas em aulas expositivas e provas. Essa contradição entre comunidade-objeto acabou gerando outras séries de contradições nas outras relações do sistema de atividades. Abaixo, segue cada relação entre os elementos do sistema de atividades analisadas segundo o esquema proposto por Mwanza (2000):

Sujeito - Ferramenta - Objeto: Alguns alunos afirmaram não ter conseguido acessar alguns recursos do REDU, como por exemplo, os "Arquivos de Aulas". Para concluir tal ação, eles teriam que clicar no ícone "Ambientes". A questão é que tal ícone não se destaca em relação aos outros elementos, o que pode indicar um problema de clareza visual. A prioridade da informação mais importante também pode ser uma questão a ser considerada, já que procurar o conteúdo das aulas é uma das primeiras e mais importantes ações possíveis no REDU.

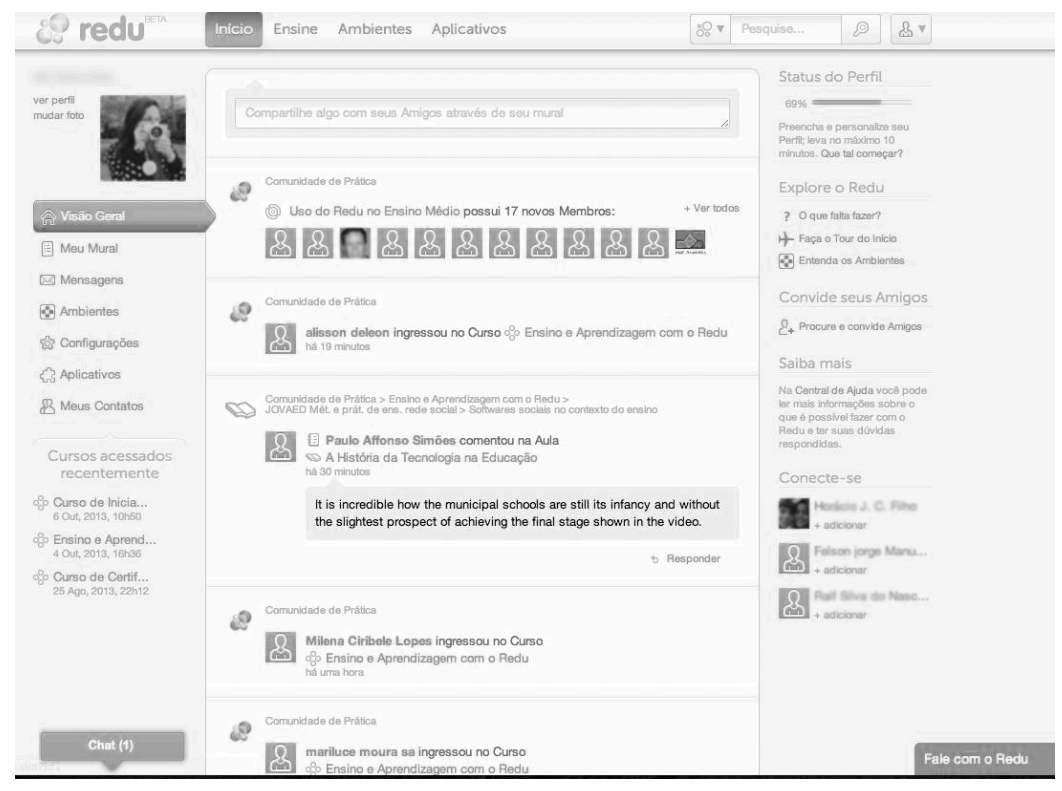

Figura 3. Tela de início da Rede Social Educacional (REDU).

Sujeito - Regras - Objeto: Na atividade educacional em questão, as regras explícitas eram que os alunos realizassem a prova, atingissem pelo menos a média mínima $(6,0)$ e estivessem presentes na sala de aula. Não foi criada nenhuma regra específica quanto ao uso do REDU ou de outras ferramentas durante a atividade educacional. Portanto, cada aluno "criou" suas próprias regras quanto ao uso desses recursos. Alguns entravam no REDU para fazer exercícios, outros apenas para falar com o professor e outros simplesmente não entravam. Já as regras implícitas eram basicamente regras de boa conduta e comportamento.

Sujeito - Divisão de Trabalho - Objeto: Considerando que o objetivo do professor no REDU era criar engajamento entre os alunos para que eles discutissem e se interessassem sobre os assuntos, o seu papel seria justamente criar tarefas ou perguntas para estimular a discussão entre os alunos. O professor relatou que não sabia como criar novos modelos para que os alunos se engajassem nas discussões. 
Comunidade - Ferramenta - Objeto: Os alunos demonstraram que usaram a ferramenta para atingir o seu principal objetivo: concluir o curso, atingindo a média final. Portanto, os recursos mais utilizados foram os "Arquivos de Aulas", para estudar em casa antes das provas, o "Exercício", para testar os conhecimentos e o "Chat", para esclarecer dúvidas com o professor. Já o professor pretendia ver os alunos se interessando e discutindo com mais intensidade sobre as aulas e principalmente sobre os materiais extras de apoio. Visto que os alunos usavam o "Chat" para esclarecer dúvidas, muitas das explicações do professor se perderam, já que esse recurso não salva nenhuma conversa, sugerindo um problema de controle do usuário, já que o sistema não permitiu que o mesmo controlasse essa ação. A maioria dos alunos afirmou que não entendeu a razão da existência de um botão "Pedir ajuda" para esclarecer dúvidas. Muitos não usaram e outros ainda acharam que o objetivo era esclarecer dúvidas sobre o uso do REDU e não sobre as aulas em si, sugerindo algum problema de usabilidade como: clareza visual, já que a informação passada causou confusão, ou affordance, por alguns alunos não saberem ao certo a utilidade do recurso.

Comunidade - Regras - Objeto: Como as regras explícitas eram realizar provas, atingir pelo menos a média mínima $(6,0)$ e estar presente nas aulas, foi observado que a grande maioria das ações dos alunos foram direcionadas a isso. A contradição foi a falta de regras explícitas que estimulassem os alunos a interagir no REDU, por exemplo, realizar tarefas específicas que também contribuíssem com a média final.

Comunidade - Divisão de Trabalho - Objeto: Como os objetivos dos alunos e do professor nesta atividade educacional eram diferentes, cada qual agiu da forma como achou ser mais satisfatória para a concretização dos objetivos. O professor foi visto tentando interagir mais no "Mural de Discussão", enquanto que os alunos focavam mais nos exercícios e no "Chat", buscando esclarecer dúvidas individuais com o professor.

\section{Conclusão}

Para que uma atividade educacional aconteça da melhor maneira possível com apoio de plataformas mediadas por computadores, o design da ferramenta, o uso adequado de seus recursos e as tarefas de aprendizagem propostas precisam estar perfeitamente alinhados. Nesse sentindo, a Teoria da Atividade se mostrou como um importante quadro-teórico, pois permite a ampliação do contexto da análise de uso, não focando apenas na ferramenta em si, mas também nos elementos da atividade como um todo e no seu contexto social.

Com base nas ferramentas analíticas da TA, a partir da identificação dos níveis de atividade (tríade Atividade-Ação-Operação), do Sistema de Atividades e da análise das contradições entre os elementos deste sistema, pôde-se identificar questões sobre o uso da plataforma REDU e direcionar para algumas possíveis falhas de usabilidade. Os seguintes principais problemas foram identificados: (a) tensões entre os objetivos do professor e dos alunos; (b) falta de regras explícitas para estímulo ao desenvolvimento de atividades engajadoras; (c) pouco uso do mural de discussão, onde a colaboração grupal é mais ativa; (d) problemas de hierarquia da informação nas funções e ícones da plataforma. Além disso, os resultados apontam para falhas nos seguintes princípios de usabilidade: clareza visual, affordance, controle do usuário e priorização da funcionalidade e informação mais importante. 


\section{Referências}

Abreu, J; Lima, L; Souza, F; Gomes, A. (2011) Análise das Práticas de Colaboração e Comunicação: Estudo de Caso utilizando a Rede Social Educativa Redu. In: Simpósio Brasileiro de Informática na Educação, 22., Aracaju.

Bellamy, R. K. E. (1996) Designing Educational Technology: Computer-Mediated Change. In: Nardi, B. (Ed.). Context and consciousness: Activity Theory and Human-Computer Interaction. Cambridge, Mass., MIT Press, pp: 123-146.

Boyd, D.; Ellison, N. (2007) Social Network Sites: Definition, History and Scholarship. In: Journal of Computer-Mediated Communication. v. 13, p. 210-230.

Jordan, P. W. (1998) An Introduction to Usability. Londres: Taylor \& Francis Ltda. Kaptelinin, V. (2013) Activity Theory. In: Soegaard, Mads and Dam, Rikke Friis (eds.). The Encyclopedia of Human-Computer Interaction, 2nd Ed.. Aarhus, Denmark: The Interaction Design Foundation. Disponível em: <http://www.interactiondesign.org/encyclopedia/activity_theory.html> Acesso em: 18 set. 2013.

Kaptelinin, V.; Nardi, B. (2006) Acting with Technology: Activity Theory and Interaction Design. Massachussetts Institute Technology (MIT) Press.

Kuutti, K. (1996) Activity Theory as a Potential Framework for Human Computer Interaction Research. In: Nardi, B (Ed.) Context and consciousness: Activity Theory and Human-Computer Interaction. Cambridge, Mass., MIT Press, pp:1744.

Machado, J. R.; Tijiboy, A. V. (2005) Redes Sociais Virtuais: um espaço para efetivação da aprendizagem cooperativa. In: Novas Tecnologias na Educação. CINTED-UFRGS, v. 3 , n. 1 .

Marteleto, R. (2001) Análise de redes sociais: aplicação nos estudos de transferência da informação In: Revista Ciência da Informação, Brasília, v. 30, n. 1, p. 71-81, jan./abr.

Morrison, D. (2003) Using Activity Theory to Design Constructivist Online Learning Environments for Higher Order Thinking: A Retrospective Analysis. In: Canadian Journal of Learning and Technology. Disponível em: $<$ http://cjlt.csj.ualberta.ca/index.php/cjlt/article/view/87/81>. Acesso em: 10 set. 2013.

Mwanza, D. (2000) Mind the Gap: Activity Theory and Design. In: CSCW'2000 Conference, Philadelphia.

Nielsen, J. 10 Usability Heuristics for User Interface Design. 1995. Disponível em: <http://www.nngroup.com/articles/ten-usability-heuristics/>. Acesso em: 16 set. 2013

Norman, D. (2006) O design do dia-a-dia. Rio de Janeiro: Rocco.

Patterson, J; Lockyer, L. (2008) Integrating social networking technologies in education: a case study of a formal learning environment. In: Eighth IEEE International Conference on Advanced Learning Technologies.

Preece, J.; Rogers, Y.; Sharp. H. (2013) Design de Interação: além da interação homem-computador. Porto Alegre: Artmed Editora. 